If others can afford to reject those rules for tracing human passion to its source in sin or disease, which are the crystalization of all legal wisdom from the beginning, and in accordance with which Cain was found guilty by the great Judge, we have only to say we cannot. That they afford but a dim light where all can be known only to Omniscence, is what we should expect; but this cannot be a reason for deserting them to follow the ignis fatuus of moral insanity.

\title{
PROVISION FOR TIIE INSANE POOR IN THE STATE OF NEW YORK.*
}

BY GEORGE COOK, M. D.

The Legislature of the State of New York, on the 30th day of April, 1864, passed an act by which the Secretary of the State Medical Society, the late Dr. S. D. Willard, was authorized "to investigate the condition of the insane poor in the various poor-houses and other institutions where the insane poor are kept, not including, however, such institutions as are now required by law to report to the Legislature of the State." Dr. Willard made the investigation in the manner prescribed by law, and submitted his report to the Legislature at its annual session in 1865. "The facts elicited by this investigation," says Dr. Willard, "are too appalling to be forgotten, and too important to be thrown aside. In order to make room for recent cases and such as afford

* Read before the Association of Medical Superintendents of American Institutions for the Insane, at the Annual Mecting, held at Washington, D. C., April 24, 1866. 
promise of relief or cure by treatment, and those are constantly urging for admission, and humanity demands that they shall not be turned away, it becomes necessary for the State Asylum to return to the counties by which they have been supported at the asylum many chronic and incurable cases. In many instances the counties have little or no disposition to send recent cases there, prompted by the idea that they can be supported at a less expense in a county poor-house. The State has grown immensely in population, and in due ratio the number of its insane has increased, until its State Asylum is filled to its utmost capacity, and the tide of its overflow has set back upon the county poor-houses; and they too have become filled to an excess of human misery, degradation and wretchedness that wrings a cry of distress from the heart of every philanthropist."

These extracts are made from Dr. Willard's report in order to show, on the authority of one commissioned by the Legislature of our State, the sad and neglected condition of the chronic insane poor in our county poorhouses. If any one has a desire to know all their wretchedness and misery, they will find the details given in Dr. Willard's report, also in a report made in 1856, by Senators Spenser, Bradford and Lee.

The message of his Excellency, Governor Fenton, to the Legislature in 1865, refers to the condition of the insane poor in the county houses, and contains the following statements and recommendation :

The Legislature of 1864 directed an investigation into the condition of the insane poor confined in the various county poor-houses. A report by Dr. S. D. Willard will be duly presented, showing the deplorable condition of this most unfortunate class. There are in fifty-five counties, not including New York and Kings, thirteen hun- 
dred and forty-five lunatics, confined in poor-houses or poor-house asylums, nearly all of whom are incurable. Many have become, and others are fast becoming incurable from inefficient care and treatment. The time has arrived when legislative provision for them should be made. The propriety of establishing an institution for incurables; an institution that shall relieve county authorities from the care of the insane, should be deliberately considered.

More than one-fourth of this number of insane are capable of some labor. To what extent this labor, organized and systemized, might be made productive in the maintenance of an institution, under well directed medical supervision, is likewise worthy of consideration.

The question being thus presented to the Legislature, the result was the creation of the "Willard Asylum for the chronic insane and for the better care of the insane poor," by an act passed April, 1865; the death. of Dr. Willard at this time suggesting the perpetuation of his name in this connection.

Before entering upon a discussion of the action taken by the Legislature, and in order to present the subject for intelligent consideration, I will state, as concisely as the nature of the subject will permit:

1st. The existing provision for the insane poor in the State of New York, and the laws pertaining thereto.

2d. The design of the Willard Asylum, and what it is intended to accomplish.

The State Asylum, at Utica, which, at the present time, accommodates about 600 patients, is the only State provision made for the insane poor. The counties of New York and Kings have county asylums. Two classes supported at public expense are received at the Asylum at Utica-the indigent and pauper. The county judges are authorized to send patients in indigent circumstances, but not paupers, who have been insane less than one year, and such patients may remain two years unless 
they sooner recover. The county superintendents of the poor send patients of the pauper class either to the State Asylum or to the county poor-houses. Those sent to the State Asylum by the superintendents of the poor are mostly recent cases. These are subject to removal by the superintendents of the poor, and the law also provides for the removal of patients of the indigent or pauper class, when, in the opinion of the superintendent of the asylum, they are not likely to be benefited by remaining longer, and the room they occupy is needed for recent cases.

Seventeen years ago the State Asylum began to return the chronic insane to the county poor-houses. Under the operation of our State lunacy laws, the insane population of these receptacles has been yearly increased, from this and other sources, until the number thus left unprovided for approaches fifteen hundred.

The act creating the Willard Asylum contains, among others, the following important provisions :

1st. That all cases of insanity of less than one year's duration, shall be sent to the State Asylum, at Utica.

2d. That after the completion of the Willard Asylum no more chronic insane shall be sent from the State Asylum to the county poor-houses, but shall be transferred to the Willard Asylum.

3d. That when the Willard Asylum shall be ready for the reception of patients, the Board of Trustees and the Governor of the State shall designate the counties from which the chronic insane now in the county houses shall first be sent to said asylum.

The design of the Willard Asylum is to take the chronic insane poor just where the former lunacy laws of our State fuiled to make provision for them, and left 
them to fall into the county house receptacles; it will take those who, under the operation of the same State laws, have been placed and kept in these receptacles for many long and weary years of wretchedness, and provide for them in a humane and christian-like manner, in an asylum built for their special care and treatment, under the supervision of a Board of Trustees to be appointed by the Governor and Senate, with a competent medical superintendent as the chief executive officer.

I am informed that the plan of building comprises a hospital structure for the paroxysmal, excited and grossly demented, with sections of cottages, plain and inexpensive in their construction, for those whose condition is such as to permit of their being employed in agricultural, horticultural, or other industrial pursuits, with benefit to themselves and to the asylum. It is believed that the plan of building here indicated will materially reduce the cost of construction, allow of a system of classification and general management which will considerably diminish the cost of maintenance; at the same time the health and happiness of the patients will be in the highest degree promoted. This plan also permits of expansion in such a manner as to obviate the objections to a large establishment under one roof. It would seem that such a design should receive an earnest "God speed" from every man who has sympathy for human infirmity and suffering.

The Willard Asylum is farther designed to supercede the system of providing for the chronic insane in the poor-houses, and to this part of its. destined work I attach the greatest importance. When it shall be completed, no more chronic insane will pass from the care of the State Asylum to the county poor-houses. The law

Vor. XXIII-No. 1.-G. 
will then provide for their continued care and treatment by sending them to the Willard Asylum. It will take from the county houses some hundreds of this class, place them in a properly constructed asylum, care for them in accordance with medical and humane ideas, develop their industrial capacities and resources, and demonstrate the fact that they can be properly provided for at a cost per week which will place such care within the reach of every county, thus opening the way to the complete abandonment of county house receptacles. This would also seem to be an object worthy of all commendation.

In short, the friends of the Willard Asylum claim that the act creating it is a step in advance of any hitherto taken in the State of New York; that it recognizes for the first time a vitally important principle by which the right of the recent and chronic insane to proper care and treatment, under State supervision, is acknowledged, and provision made for them by the State Legislature. They claim that the hospital system in the State of New York, by which the recent cases are specially provided for, is incomplete; that provision for the chronic cases is also necessary to make a system of caring for the insane comprehensive. This essential requisite the Willard Asylum is designed to supply.

Having thus called attention to the condition of the chronic insane, resulting from the operation of our lunacy laws, and in general terms indicated the nature and design of the new asylum, I pass to a consideration of some of the objections which have been made to its establishment. In doing this it will be necessary for me to follow the objectors, and enter upon a discussion of details which I have hitherto purposely avoided. By 
pursuing this course I have hoped to avoid needless repetition.

I have only to remark before entering upon this branch of the subject, that the friends of the new asylum for the chronic insane find their plans and purposes first presented to the medical profession and the general public in the language of those who do so for the purpose of opposing and overthrowing them. Without waiting for a development of these plans, or for a fair exposition of them from those who believe them worthy of adoption, an assault has been made upon them, commencing in our own State and sustained therein, by reference to the opinions of superintendents of asylums in other States, who have recently devoted no small space in their annual reports to the discussion of this subject. I am not disposed to complain of this; perhaps the cause of truth and humanity may be as effectually subserved in this way as in any other; but it has seemed to me that as the Association of Superintendents, at their last meeting, appointed a committee to investigate and report upon this subject, it would have been more courteous for the members of the Association to have awaited the report of their committee. In consequence of this action, the friends of the asylum for the chronic insane in the State of New York find themselves compelled to defend the position they have taken in support of the legislative action of 1865 .

It is asserted in a general way that in establishing an asylum for the chronicinsane, we are "making a retrograde movement," that " upon no subject connected with provision for the insane has the verdict of the profession been more unanimous than in their condemnation of asylums for incurables." It is farther asserted that the "separa- 
tion of recent from chronic cases is wrong in principle," and leads to abuses in practice; that it is not for man to "pronounce the decree of incurability and consign the insane to life long hopelessness," and much more in the same vein. This manner of presenting the subject is more specious than accurate. If one were to listen to what has been said in opposition to separate provision for the chronic insane in the State of New York, having no knowledge of their actual condition, he would suppose that they were now amply provided for in curative hospitals, and that some restless, dissatisfied theorists, not content to leave them in such good care, were, in violation of all professional and humane ideas, endeavoring to thrust them out and precipitate them into a hell, over the gateway to which shall be inscribed,

All hope abandon, ye who enter here.

But instead of this we find that under the sanction of law the chronic insane to the number of about 1,500 are now confined in the county poor-houses, some of them having been returned from the State Asylnm as incurable, others never having had the benefits of asylum treatment. Bear in mind their condition as described by Dr. Willard. Could there be a separation more broad and deep than is thus made by the laws as administered in the State of New York, between the so-called curable and incurable insane? On the one side all the care, comforts and appliances of a modern hospital for the insane; on the other all the neglect, confinement and filth of the poor-house system. And observe that the separation has been made by the laws and its administrators, not by those who now urge better provision for the 
unfortunate class thus left, in the approving words of one who has recently spoken on this subject, "to take their chances."

In view of these facts, is it fair, is it just or right, when some special provision is proposed for these helpless and friendless insane, to meet the proposition by saying, "you are taking a step backward," "you are lowering the standard," "the curable and incurable insane ought not to be separated," "to care for them in separate institutions is wrong," "and it can never be economical to do wrong"? And yet for the last fifteen years has this standard, for which such jealous regard is now shown, been trodden under foot by those who have administered our lunacy laws, and been trailed in the filth of our county house system. The backward step which was taken years ago has become entrenched in the strongholds of county policy and poor-house economy; the decree of incurability which we are now told is so dreadful in view of the transfer of patients from one asylum to another, has often fallen from the lips and pens of our asylum superintendents, thereby consigning patients to county house receptacles for reasons of incurability.

This separation of the recent and chronic insane having been made in the State of New York, and having become firmly established in the operation of our former lunacy laws, the question presented for solution was clearly this: What practical measure could be brought forward which would first check the stream of insanity flowing into the county poor-house receptacles, bridge over the gulf lying between our present hospitals and these receptacles, and ultimately secure their entire abandonment by the adoption of a comprehensive system of 
care, comprising within its provisions all the insane poor of the State?

Could this be attained by the erection of one or more buildings on the plan of our present State Asylum, to be governed by the same laws in regard to the admission and discharge of patients?

The Association of Superintendents of American Asylums have decided that 250 is the maximum number which should be provided for in one hospital. If two such hospitals were to be built, some slight relief would doubtless be experienced, the public and professional conscience would be, for the time, soothed, and we should go on for a few years in the future as we have done in the past. The new hospitals would gradually reach the condition of the present one, and in their turn overflow into the county house receptacles, which would of necessity continue to hold the great mass of chronic insanity; and when some startling exposure of abuse and neglect should again be made, another hospital would be proposed, and after years of delay would, perhaps, be erected. Thus we should go on, and while adding to our number of hospitals, yearly add to the number of chronic insane in the county houses. Is this the solution of the question proposed ? Or will it be said, change the law, provice for the retention of the chronic class, and erect hospitals on the present plan for all the insane, each hospital to receive the recent and chronic cases of a certain district.

For fifteen years efforts have been made, without success, to secure the passage of a bill through the Legislature of the State of New York for one or more State hospitals of this character. What probability is there that a scheme will now be adopted which would involve 
the erection of five or six hospitals and the expenditure of two millions of dollars to provide for the insane poor now in the county houses? County authorities are. in many cases, reluctant to send even their recent insane to the State Asylum for treatment; they are unwilling to incur the expense. They would not send the chronic insane except on compulsion; and a compulsory law for such a purpose would meet with determined opposition. No such provision for the chronic insane will ever be made in the State of New York. If there ever was a time when such a result could have been reached, that time has passed beyond recall.

Under these circumstances, and with a knowledge of all the facts, Dr. Willard made his report, and Governor Fenton recommended the subject to the Legislature as worthy of earnest consideration. To leave the chronic insane poor in the county houses, in their present deplorabie condition, was wrong; to provide for all of them according to the propositions of the $\Lambda$ ssociation of Superintendents for the construction and organization of State hospitals was impracticable. Only one other method presented itself-separate provision in an asylum of cheaper construction, and with diminished cost of maintenance. This seemed to offer a practical solution of the difficult question, and was adopted.

This statement of facts is, perhaps, a sufficient answer to the general objection brought against separate asylums for the chronic insane. The separation being already made, even supposing that separate provision is not the very best that could be made, yet if it is the only one attainable, is it not wiser to take it rather than adhere to the unattainable, and get nothing? 
An editorial article in the Journal of Insanity for October, 1865, which, by the way, appears to have suggested the continued discussion of this subject, assails the Willard Asylum in a spirit so unfair, and is so inconsistent even with itself, as to demand some particular notice. This article is noticed here as a marked example of the style of discussion which has characterized the ill concealed hostility toward this new institution.

It is stated by the writer that "thirty per centum would be an approximate estimate for the acute or recent cases under treatment at Utica," and considerable space is occupied in showing how difficult it is, under the present system, to "discharge the duties of the medical office." "These favorable cases," says this authority, " receive the greatest share of the physician's solicitude and care," consequently we are left to conclude that the smaller share only is left for the seventy per centum of chronic cases. Yet we are told on the following page "that the treatment of chronic mental disease is the peculiar province of medical science, and that its successful practice demands the highest qualities of the physician and the widest range of the materia medica." If this be true, does it not follow that the highest welfare of every seventy chronic cases is sacrificed for the sake of the thirty recent cases? If, under the present system, the time and attention of the medical officers must necessarily be so largely occupied by the recent to the neglect of the chronic insane, why object to separation? And why assume, as is done in this article, that under separate care the chronic insane are to be still more neglected? Does he, and those who agree with him, intend to assert that the presence of these recent cases, occupying most of the time and attention of the medical 
officers, is necessary to sccure the best care and treatment to the chronic cases, upon whom they have only time to bestow a hasty glance and a good morning? I confess to being so obtuse as not to be able to discover just where the "highest qualities of the physician," which we are told are required for the treatment of chronic insanity, are brought into active exercise under this system.

An asylum which should retain its chronic cases under care, would soon have but few yearly vacancies for the reception of recent cases. Unless we are content with the county house system, or establish separate asylums for the chronic class, this course must be adopted. The result will be that in State asylums thus managed the passage of a few years will fill their warls almost entirely with old cases, with, perhaps, ten per centum of recent cases. Dr. Bucknill stated that of 600 patients under his care, he regarded only forty as curable.

The argument, or rather the assumption, of those who stand prominently forward in opposition to the plan of the Willard Asylum is clearly this : that the presence of these few recent cases is essential to the care of the greater number of old cases; that without the former, the latter would be liable to abuse and neglect so gross as to warrant them in calling the place where they should be separately cared for, a hell in misery and hopelessness. Do they wish to be understood as saying that in the discharge of the duties of their official position they have no regard to the Divine commands which bear upon human conduct; that they have no regard to human laws, which they profess to obey; that boards of managers are only useless appendages; in short, that the only thing which can or does secure the poor, helpVoL. XXIII.-No. I.-H. 
less chronic insane under their charge from oppression and abuse, is the ten or thirty per centum of recent cases placed under the same roof. Such would be the legitimate deduction to be drawn from the arguments used against separate provision for the chronic insane. May I not be pardoned for saying that the arguments are absurd and the conclusions unworthy of belief?

Under an asylum system receiving and retaining the recent and chronic insane indiscriminately, I admit that the highest good of either one or the other class must sometimes, perhaps often, be sacrificed. When patients of the two classes are placed together in the same wards, and the recent cases have bestowed upon them the requisite medical attention, if they are carefully observed by the attendants, diverted by amusements, taken out for gentle exercise, then the chronic insane must have the same treatment, or be left to idleness. If the latter, however, are given some regular, active employment, which but serves to promote their health and happiness, the recent cases must be neglected. If you give to each class, when thus mingled together, the care best suited to them, then you largely increase the cost of attendance. Here you have a reason why the labor of patients is often made of so little value under the present system.

In other words, there are two distinct ends to be attained, requiring different construction, organization and management. If we attempt to attain these ends by a commingling of the two classes in the same wards, we meet with conflicting interests, and are compelled, frequently, to sacrifice the highest good of one class to the other. Need I add that the sacrifice falls mainly upon the chronic class? This practical difficulty in asy- 
lum management would be removed by separating the two classes.

We are also told in this article that "there is no subject connected with provision for the insane upon which the verdict of the profession has been more unanimous than their condemnation of asylums for incurables." The Willard Asylum is. designed to make provision for the chronic insane, and I suppose the writer assumes to pronounce them all incurable, and therefore this is to be an asylum for incurables existing under the condemnation of the profession; else there would be no point to his assertion. And then he proposes to inscribe over its doors Dante's incription over the portals of hell. Think of this for one moment; call to mind where these patients are to-day, look in upon them in their filthy, narrow cells, the only care bestowed upon them coming from the hands of their pauper associates; behold them as they come forth from their degradation and misery to the care and comforts of an asylum under State supervision, and judge ye what manner of spirit could prompt the hand that aimed to attach such a stigma upon so great a charity!

I have only to say, in reply, that the Willard Asylum is not simply an asylum for incurables, though doubtless the largest number of the patients it is designed to provide for are beyond all human hope of restoration. $\Lambda$ gain, asylums for the chronic insane are not unanimously condemned by the medical profession. So far is this from the truth, that two of three superintendents who have had charge of our State Asylum, observing the defects of the present system, have commended their establishment as necessary to a comprehensive system of provision for all the insane poor. I quote from their 
published reports on this point, and if it were necessary to my present purpose I could fortify their opinions by numerous quotations from American and foreign writers. But it is my design to confine the discussion as much as possible to the condition and wants of the insane poor in the State of New York.

Dr. Brigham says: "I hope the time will speedily come when, in every State, good asylums will be provided for this class of patients." He says much more upon the subject, to which I shall have occasion to refer when I come to speak of employment.

Dr. Gray says: "The partial and limited provision for the insane (referring to the present hospital system) must give way to some system more comprehensive and just, and more in accordance with the civilization of the age. In the care of the poor and the insane, much is yet to be done. $\Lambda$ system based upon the wants and condition of the various classes to be relieved, must be developed and put into operation. Hospitals, with all their varied appliances for the treatment of acute diseases, must still be demanded, but for the care of chronic insanity, more simple and less expensive arrangements will be required and adopted."

To all of which I respond with a hearty amen. Here we have a very good professional foundation for the Willard $\Lambda$ sylum. Instead of a unanimous condemnation of special and more economical provision for the chronic insane in the State of New York, we find a unanimous commendation of it from all the Superintendents of the State $\Lambda$ sylum who have placed their views upon record.

Hope, we are reminded by this writer, "possesses a powerful influence in promoting recovery from disease." The truth of this is beyond question. And having 
assumed the right to inscribe over the gateway of the Willard Asylum Dante's inscription to the portals of hell, he adds, "deprived of auspicious hope, branded with incurability, under the twofold burden of disease and despair, the sufferer from chronic lunacy drags through his miserable life." And in a marginal note he says, "the medical solecism of pronouncing any patient incurable we deem hardly worthy of notice." Yet observe how ready he is to put the term in the mouths of those who use it not. He will not find the word incurable in the act creating the Willard Asylum, and I know not by what right he assumes to use the term in connection with it. Would he have us understand that he regards "chronic" and "incurable" as convertible terms?

And what would be thought of the proposition to write Dante's inscription over the entrances to the asylums for the aged poor, whose hope rests only beyond the grave; over the asylums for the deaf and dumb and the blind, for whom human power can only bring relief, not restoration; over the special hospitals into which are gathered the victims of phthisis, and other forms of chronic disease, not always or generally within the reach and control of human agencies, other than those which serve to alleviate human suffering? The Willard Asylum is designed to apply the same principle to the hitherto neglected chronic insane, to provide for their peculiar wants, and in so doing it is claimed that instead of abandoning hope, there is extended to this unfortunate class the strong hand of human aid and sympathy. I venture to say that an asylum erected, organized and managed for the express purpose of providing for the chronic insane, will present as good a foundation for hope to rest upon as the county houses of the State of New 
York ; and some patients who have been sent back from the State Asylum, in the language of this writer, "branded with incurability," and pronounced as beyond hope of benefit, have recovered even in them. I may venture even farther, and say that $I$ hope for more frequent recoveries under such a system of care as is proposed at the Willard Asylum than under one where the so-called "favorable cases receive the greatest share of the physician's solicitude and care."

It is well known by all who have lived long among the insane, that the great majority of the chronic class give very little thought to the future; many of them are demented, many have no consciousness of mental infirmity, and others become strongly attached to any place in which they are treated with kindness. It is in the recent cases that the influence of hope possesses the strongest power. And the effect of placing such patients in a ward where nine-tenths of their associates are old cases, is often detrimental. They learn quickly that most of those around them have been many years in the asylum; they sometimes see and hear much that is disagreeable and discouraging, and they are not slow in entertaining apprehension and fear that they are to follow the same downward pathway. In some cases the conviction becomes so strong as to work serious injury. Dr. Ray says that he would "not oppose the separation of the incurables, considered strictly as a measure of classification. Intimate association with epileptics, paralytics and the grossly demented, is disagreeable to most curable patients, and decidedly prejudicial to their welfare." Thus it appears, that as a principle of classification, the separation of the chronic from the recent cases is founded upon the highest interests of both classes. That it is 
better for the recent cases, because it secures to them the undivided care and attention of the medical officers, surrounds them with all the appliances of a modern curative establishment adapted to their special wants, free from the encroachments and conflicting interests of a greatly preponderating number of old cases. Better for the chronic insane to be provided for either in separate asylums or in buildings detached from the hospital, because an organized classification and system of management can then be carried forward best adapted to their peculiar necessities. This disposes of the objection most strongly urged against separate provision for the chronic insane.

We are further informed in this editorial article, that "from natural affection, as well as to avoid the implied disgrace of being on the roll of pauper lunatics, patients would be removed from such institutions and provided for in their respective families." And from the same page I quote the following sentence, by which we are told what these sensitive persons will do to improve the condition of their dear relatives after removing them: "To promote the comfort and security of the domestic circle, some attic room or outbuilding is made secure and dark for the permanent abode of the unhappy wretch, and chains, cages and cruelty eventually usurp the place of that tender care which it is the object of the law to realize." What sort of natural affection is this which would remove its kindred from the humane care freely bestowed by the State, and chain and cage them in attics and outhouses? Hundreds of these patients are now confined in the poor-house receptacles, some of them in the most deplorable condition, paupers themselves, surrounded by paupers, cared for, or rather neglected by 
paupers, friendless and forlorn, and yet we are told in apparent seriousness that if we venture to make special provision for this class, their relatives, coming from some unknown place, prompted by natural affection and to avoid the disgrace of pauperism, will rush to their rescue, and in the fulness of their love and pride, chain and cage them in attics and outhouses! Comment is superfluous upon such glaring inconsistency.

The importance and value of labor remains to be noticed. Upon the question of employing the chronic insane poor in agricultural and horticultural pursuits there is but one opinion held and expressed by all who have had and who now have the care of patients belonging to this class. I might fill pages with quotations showing the great benefits to these patients of this kind of labor.

But as regards the value of their labor in contributing to lessen the cost of their support, there is a difference of opinion. The facts are uniform; that it is for the highest good of these patients to be employed, is unquestioned; that they can and actually do labor is also true. Is their labor then of no value in lessening the expenses of our isylums?

I desire here to direct attention to the fact that the Willard Asylum is not designed to try an experiment, but to apply a principle. It does not propose to do what has not already been done in making the labor of patients serve to diminish the cost of support. In some of our State asylums this has been done, and we have heard no word of condemnation. A few brief extracts from published reports will suffice to establish the fact in question.

I)r. Woodward says, "the agricultural and horticultural operations of the hospital materially lessen the expenses of the establishment." 
Dr. Brigham states: "The number able to labor will vary in different institutions. In some, especially in those that have been long established, are many old and incurable cases that are made much happier by daily labor. In such institutions these may be classified, and do much toward supporting themselves." In speaking of asylums for the chronic insane, he adds: "I am clearly of the opinion that with a good farm connected with such asylums, and the judicious arrangement and management of shops, one-half of the incurable insane of our country would perform sufficient labor to support themselves, and would be the happier and more healthy for the exercise."

Dr. Rockwell writes: "Their labor tends directly to their restoration and indirectly to lessening their expenses. Whatever they earn increases the income of the institution and lessens the expenses of the whole." The charge per week at the Vermont Asylum, where the above was written, was two dollars, and at no time during the.late war has the charge been over two dollars and seventy-five cents per week.

Dr. Harlow says: "With what we get from the farm, we are able to meet the current expenses with the rate of board and treatment down to the low sum of two dollars and fifty cents per week." Male patients in large numbers are employed on the farm.

Dr. Chandler remarks : "Labor ranks high among the curative means used here, and it is made a source of profit also."

Dr. Gray says : "Cases of dementia, and quiet persons laboring under chronic mania, are not generally inclined to as much activity as is really necessary for their general health. These can work regularly and Vol. XXIII.-No. I.-I. 
moderately several hours a day, and they will thereby promote their comfort, cheerfulness and contentment. Here occupation is particularly desirable for the welfare of the individual ; not only to insure greater contentment, but to prevent listlessness and inactivity, and the unpleasant personal habits too generally consequent upon idleness. Farther, many are thus made quite useful in contributing to their support, a duty which ought not to be lost sight of." For the year 1865, the net value of the farm products was about $\$ 12,000$, being a little more than twenty dollars a year for each patient. This is about thirty-eight cents a week for each patient, contributed by the farm and garden. A large part of the work was done by patients.

Pages might be filled with similar quotations from the reports of American asylums, but these cover the whole question under discussion. They show conclusively that the labor of the chronic insane poor can be, and has for years, been made to contribute to their own support. It may be that in some institutions, having under care large numbers of recent cases, the labor of patients is of little comparative value. It may be that in our corporate hospitals which provide mainly for those not accustomed in health to manual labor, that employment is not made in any considerable degree remunerative. It is quite possible that some superintendents of State asylums fail to so employ their patients, or, employing them, fail to apply their earnings to the reduction of the cost of their support. But these are only negative results. One man takes a farm and works it, and year by year impoverishes himself. Another man takes the same farm and works it profitably. The farm clearly is not at fault; it yields abundantly to the man who manages it properly. So 
with any occupation involving pecuniary results. Under some systems of management, the labor of the chronic insane poor has not been made to contribute to their support; it is certain, however, that their labor has been profitably applied in some asylums, and that under a judicious system of classification and a proper industrial organization, all they earn by their labor will go to diminish the current expenses.

Some strong expressions have been used by some asylum superintendents of late, which tend to depreciate the value of this labor, and to create an impression that it is of no pecuniary value whatever. As an illustration, Dr. Curwen, in his report for the year 1865, says : "No fallacy is more fanciful or more expensive than that the chronic insane can be made to support themselves, or to assist in providing for their own maintenance." I am not aware that any one has proposed that they can or should be made self-supporting. As to the fallacy of insane patients assisting in their support, let Dr. Curwen answer in his own language. I quote from the same report. He says: "The products of the farm and garden have been such as to enable us to present a very favorable statement. In securing this result we have been materially assisted by the labor of the patients, who have received great benefit from the assistance which they have given in this way." Is there not something conflicting in these statements?

Dr. Ray, in his last annual report, enters at some length upon a discussion of the question of employment and provision for the chronic insane, and in a general spirit of fairness, for which I thank him. Yet when he says, "Whereas, the object at first was to place all these persons (chronic insane) in the hospitals, the question 
that agitates the philanthropists of our day is, how to get them out of the hospitals." I beg to remind him that his remark does not apply to the State of New York. We have some patients of this class not in hospitals. And when he states that "in a hospital like this (Butler Hospital,) receiving all sorts and conditions of men, from the town pauper up to the millionaire, many of them unaccustomed to labor, and many more whose mental affection is coupled with serious bodily ailment, such as epilepsy, paralysis, extreme depression of the vital powers, not much labor could be reasonably expected," and subsequently adds, "during one and twenty months forty-two different male patients have been employed in labor, amounting to about three-sevenths of the whole number under care, and to about four-sevenths of such as had been accustomed to manual labor," and "that the time thus occupied amounts in the aggregate to 6,382 days," it seems to me that he admits substantially all that is claimed by those who believe that the labor of the chronic insane poor can and ought to be usefully applied. Surely this labor was of some value. And if Dr. Ray can secure such results with the class of patients he describes, is it not fair to conclude that with patients coming from the laboring classes and from the chronic insane, more favorable results could be reached? And surely no one will say that this labor, expended mainly upon a farm and garden, would not serve to reduce the cost of support.

If it is better for these patients to labor regularly and moderately, as is universally conceded; if they do labor and earn something, I can see no reason why their employment should not be so arranged and so systemized, and the asylum so managed as to apply what they earn 
towards defraying current expenses, especially as the question of cost now stands as a barrier between hundreds of them and any asylum provision whatever. They are kept in county houses because it costs so much to provide for them in State hospitals. Diminish the cost without sacrificing the welfare of the patients, and the way is opened to asylum provision for all the insane. This being true, is it not more in accordance with the spirit of a true humanity to go forward in an earnest effort to solve this question of care for the chronic insane, than to rest content with a survey of the difficulties surrounding it? While Dr. Ray admits that " no community, here or abroad, has yet furnished hospital accommodation for all its insane, and that it is less likely than ever to be done in this country while staggering under the burden which the great national contest has heaped upon us," he is not yet satisfied of the utter impracticability of providing for all our insane in hospitals. I am convinced that some modification is required. And if Dr. Ray has any plan to propose, if there is any better practical solution of this question, I beg that it may be brought forward now. In the State of New York we are earnestly seeking for some way out of our county house abominations; we are satisfied that hospitals alone will not help us. We would like to have assistance in the efforts we are making to improve the condition of our chronic insane; at least, we would ask that no needless obstructions be thrown in our way.

In a hospital receiving and treating recent cases, the external and internal arrangements over the whole house must be adapted to their peculiar wants; in an asylum for the chronic insane, only the excited, paroxysmal, and grossly demented would require the expensive arrange- 
ments of a modern hospital. The large number embraced in the quiet, cleanly and industrial classes, could be provided for in buildings of plain architectural design, durable, and yet economical in their construction, having associated dormitories, and without expensive systems of warming and ventilation. By the adoption of such a plan of building, the cost of construction may be reduced one-half below the average cost of our modern State hospitals, without, in any degree, sacrificing the comfort of the patients. These less expensive buildings for the quiet and industrial classes might be erected upon the farms connected with our State hospitals, and separate provision be thus made for the chronic insane. I am inclined to the opinion that some plan of this kind will be eventually adopted.

It is a part of the projected plan of providing for the chronic insane in the State of New York, to classify them with reference to their fitness for special kinds of employments, to give them work upon the farm, in the garden and in shops, and to apply whatever they may earn to their support. By classifying those patients who are able to labor with some regard to their occupation, placing the farmers in one cottage, the gardeners in another, and so with other pursuits, it is believed that they will be happier, and at the same time an industrial organization could be perfected which would render the labor of patients available without any more cost for attendance than if they were kept idle in the wards. For instance, an attendant having ten or fifteen garden laborers under his care, would take them all out with him to the garden for as many hours a day as the physician should direct. The supervision during the hours of labor in the open air or in the shops would cost no 
more than when they were idle, and all that they might earn would go toward defraying the cost of support.

It is not proposed that these patients shall work any more than is good for their health of body and mind; no more than similar patients now work in our State asylums; but it is proposed to apply to them the ordinary rules of organization and division of labor necessary to render any branch of industry a pecuniary success. And I maintain that this is right in principle and humane in its application. Right in principle, because it secures for the benefit of these patients the avails of their labor, thereby removing out of the way one of the great obstrcles to asylum provision for them. That obstacle in the State of New York is the cost of support under the present hospital system. It is humane because it is best calculated to promote their well being, happiness and contentment.

I have aimed in the preceding pages to show that the only two prominent objections made to separate provision for the chronic insane are totally without foundation.

I conclude that the separation of recent and chronic cases is founded upon correct principles of classification, and rests upon sound political economy ; that the chronic insane may be properly provided for in less costly buildings than those now erected for curative treatment; that the cost of maintenance may be considerably reduced by a judicious arrangement of agricultural and other employments for those who are able to labor; in short, that with an asylum located in an agricultural district, where all the staple articles of consumption can be obtained at minimum rates, thus managed, the average cost for the weekly support of these patients will not exceed two dollars per week. I believe that the same 
result may be secured by means of cottage buildings in connection with our State Hospitals. Nothing in all that has been said and written on this subject has in the least shaken the firm conviction which I have long entertained that in this direction lies the only way out of our present incomplete provision for the insane poor.

It is not well to sneer at political economy in its relations to the insane poor; whether we think it right or not, the question of cost has determined, and will continue to determine their fate for weal or woe. Neither is it well to conclude that a so-called standard, erected fifteen or twenty years ago, must of necessity be right, and that any and every departure from it is to meet with denunciation. It seems to me that it would be much less quixotic to carefully consider all the facts, and in making provision for the insane poor, endeavor to make an intelligent application of means to accomplish the desired end. And that end is some fair provision for all the insane poor; not hospitals for the few, and poorhouses for the many. Against this I enter an earnest protest.

No evidence could be more conclusive of the necessity of some modification of our present plan of hospital construction and organization, and of the insufficiency of the propositions pertaining thereto, adopted fifteen or more years ago, than the diversity of views recently expressed in the annual reports of asylum superintendents. Dr. Butler, Dr. Hills, Dr. Workman and Dr. Van Deusen concur in recommending provision for the chronic insane in separate asylums or in farm cottages and asylums, retaining a connection with the parent institution. Dr. Bemis suggests some important modification of the present system in the same direction, and 
goes even farther in his departure from the orthodox standard. Dr. Chipley would combine "the features of a hospital and an asylum, have a large farm upon which to give employment to the chronic class, and thereby reduce the cost of maintenance." He also thinks that instead of adhering to the dogma that limits the number to be provided for in one hospital to 250 , that the number might then be properly increased to 500. Dr. Ray would " not oppose the separation of the incurable considered strictly as a measure of classification." Dr. Kirkbride thinks that " the only proper mode of providing for the chronic insane is for every State to erect just as many hospitals as are necessary to provide for all the insane, and that the propositions of the Association of Medical Superintendents, both in regard to construction and organization, should be fairly carried out." Here we have widely differing views. The propositions referred to by Dr. Kirkbride were adopted many years ago, and were based upon the condition and apparent wants of the insane at that time. The intervening years have wrought many changes. The number of chronic insane has largely increased, and in our State the county poor-house system has assumed startling proportions. The poor-house receptacles in the State of New York are as much a part of our present provision for the insane poor as is our State Asylum.

These propositions look only to the erection of small hospitals, and the organization is mainly adapted to the treatment of recent cases : and in the practical working of the system, are not the chronic insane left to find their way to the county poor-houses? Is it not a fair question to ask whether some revision of this hospital system is not required? Will you allow it to bar the

$$
\text { Vor. XXII:-No. 1.-J. }
$$


way of those who would do something to check the growing influence and power of the county house receptacles? Are you content to have the system laid down in these propositions and developed in the practical working of our hospitals, recognized as the only one which has the endorsement of the Association? And when some special effort is made in behalf of the chronic insane, against whom this hospital system has already closed its doors, should it be met with the objection that it is not in accordance with these propositions, and therefore it must be wrong?

Those asylum superintendents who criticise separate provision for the chronic insane are not united in support of the Association propositions, neither do they agree upon any plan calculated, in my opinion, to rescue the chronic insane in the State of New York from their present deplorable condition.

Were all the insane poor of our State provided for in State hospitals, or did I believe that such provision could be obtained for them, I should not now come forward as a defender of a separate and distinct asylum for the chronic class; though I should most certainly hold the opinion that the interests of the recent and chronic cases would be best promoted by such a system of classification and care as would involve their separation. But for the fifteen hundred chronic insane in the county houses of the State of New York, against whom the doors of our present hospital system are forever closed, the protecting care of the State is now sought in some special provision.

Having made this provision for some of them under the laws creating the Willard Asylum, it remains for the State of New York to erect other hospitals for recent 
cases in convenient sections of the State, as they may be required, and either in connection with them or separately, to extend the provision for the chronic cases until none shall be left without care, and the county poor-house receptacles for the insane shall be sunk in merited oblivion. Then we shall have a comprehensive system by which asylum care and ireatment will be secured to all, whether recent or chronic. For the coming of that time many are waiting. God grant that they may not have to wait long.

\section{TWENTIETH ANNUAL MEETING}

OF THE

ASSOCIATION OF MEDICAL SUPERINTENDENTS OF AMERICAN INSTITUTIONS FOR THE INSANE.*

The Twentieth Annual Meeting was held on the 24th of April, in the city of Washington. The Association was called to order at $10 \frac{1}{2} \mathrm{~A} . \mathrm{M}$.

The following members were present:

Thomas S. Kirkbride, President, Pennsylvania Hospital for the Insane, Philadelphia, Pa.

John Curwen, Secretary, State Lunatic Hospital, Harrisburgh, Pa.

John P. GrAy, State Lunatic Asylum, Utica, N. Y.

Wm. L. Peck, Central Ohio Lunatic Asylum, Columbus, 0 .

* Reported by Francis H. Smith, Stenographer, Washington, D. C. 